\title{
Surface modification of graphene and graphite by nitrogen plasma: Determination of chemical state alterations and assignments by quantitative X-ray photoelectron spectroscopy
}

\author{
Imre Bertóti ${ }^{*}$, Miklós Mohai $^{1}$, Krisztina László $^{2}$ \\ ${ }^{1}$ Institute of Materials and Environmental Chemistry, Research Centre for Natural Sciences, \\ Hungarian Academy of Sciences, H-1519 Budapest, P O Box 286, Hungary \\ ${ }^{2}$ Department of Physical Chemistry and Materials Science, Budapest University of \\ Technology and Economics, H-1521 Budapest, P O Box 91 Hungary
}

\begin{abstract}
Multilayer graphene (MLGR) and its bulk analog, highly oriented pyrolytic graphite (HOPG), were treated by radio frequency activated low pressure $\mathrm{N}_{2}$ gas plasma (at negative bias $0-$ $200 \mathrm{~V}$, for 5 - 20 minutes). Surface composition and chemical-state alterations were delineated by X-ray photoelectron spectroscopy (XPS). Covalently bonded nitrogen of 5 15 atomic \% incorporated into the surface. The higher $\mathrm{N}$ concentration in MLGR below $100 \mathrm{~V}$ is attributed to the larger number of defects. The equal $\mathrm{N}$ content at $200 \mathrm{~V}$ indicates intensive formation of reactive sites. In-depth distribution of $\mathrm{N}$ is restricted to $2-4$ monolayers. Model calculation resulted in 23 atomic $\% \mathrm{~N}$ (at $100 \mathrm{~V}$ ) in the top graphene layers of HOPG. Three different chemical states of nitrogen (pyridine-type at $398.3 \mathrm{eV}$, pyrrole- and triazine-type at $399.7 \mathrm{eV}$ and $\mathrm{N}$ substituting $\mathrm{C}$ in graphite-like network at $400.9 \mathrm{eV}$ ) were determined from high-resolution N1s spectral region for all samples. Pyridine and pyrrole-triazine components increase preferentially with increasing bias. Alterations of the $\mathrm{C} 1 \mathrm{~s}$ and $\mathrm{O} 1 \mathrm{~s}$ spectra are discussed in a critical approach. The amount of reacted carbon was consistent with that required for the three different nitrogen and oxygen states, thus validating the proposed assignments.
\end{abstract}

\section{Introduction}

Owing to their unique physical and chemical properties, nano-carbon materials, including carbon nanotubes, graphene and graphene oxide, have been at the focus of recent

\footnotetext{
* Corresponding author: E-mail: bertoti.imre@ttk.mta.hu, Phone: +36 13826556
} 
investigations. Once their basic properties have been identified, the next main concern is their potential application. They are potential candidates for promising applications in various areas ranging from novel structural materials and field emission devices, to pharmaceutical drugdelivery vectors and also bio-sensing [1-5]. All these applications require some form of surface modification, which explains the great effort that has recently been devoted to such investigations [3-12]. In addition, detailed theoretical studies that attempt to relate $\mathrm{C}-\mathrm{N}$ atomic structures to XPS chemical shifts, have shown that these structures display large variability $[6,13]$. Moreover, hetero-atoms or surface groups may significantly influence the wetting and acid/base properties, or even the morphology of the carbon nanoparticles [7-9]. For drug carrier applications, reactive surface groups are needed to anchor bioactive molecules. In their use as reinforcing polymer matrices, tailored surface treatment not only improves their dispersion, but also assists their chemical bonding to the matrix [9,12]. Nanometric scale surface modification has been achieved recently by a novel atmospheric plasma AFM lithography technique, with the objective of preparing atomically defined electronic circuit devices on top of a graphene monolayer [14].

Recently, we have been applying radio frequency (RF) activated $\mathrm{N}_{2}$ plasma to the study of covalent attachment of nitrogen to carbon based materials, including commercially available carbon nanotubes [11].

RF cold plasma activation is a simple method for initiating gas-solid reactions to modify the surface by exciting, and also partly ionizing, the gas phase reactants. By imposing negative bias to the treated solid the positive plasma-ions can be directed to the surface with well controllable energy. This method enables one to activate the surface of the solids, create reactive defect-sites or implant the gas atoms into the sub-surface atomic layers, accommodating them in interstitial, substitutional lattice sites or in vacancies.

Microwave or radiofrequency plasma treatment of graphene or graphene oxide in the presence of $\mathrm{N}_{2}$ or $\mathrm{NH}_{3}$ has been reported as an efficient means of introducing nitrogen atom heterogeneities into the graphene layer(s). The method is solvent-free, thereby minimizing reaggregation of the graphene flakes. The temperature and the duration of the treatment allow for further fine tuning of the nitrogen content $[15,16]$. Recent reviews on the synthesis of nitrogen doped graphene or graphene oxide $[17,18]$ also underscore that the efficiency of plasma treatment in nitrogen doping considerably exceeds other methods.

Moreover, no, or very little environmental hazard is connected with the proposed RF plasma technique, owing to low energy and reactant consumption, and essentially no emission occurs. In addition, few or no residues or harmful by-products need to be dealt with. This is why this 
technique is rapidly gaining space, e.g., sterilization with oxygen plasma is widely used in biomedical practice.

For large-scale practical applications of $\mathrm{N}$-modified carbon-nanophases, a simple and economic method may be the only one feasible. This could involve, e.g., mechanical exfoliation (grinding) of the graphite precursor into few-layer graphene flakes and exposing their surface to varying extents with activated nitrogen, as we propose and demonstrate in this work. The necessary initial investment in the vacuum system and RF source will be repaid in the long term running.

Annealing of graphene or graphene oxide with $\mathrm{NH}_{3}$ is also a means of nitrogen doping that can easily be scaled, but it requires elevated temperatures (over $300^{\circ} \mathrm{C}$ ) [19-21].

Chemical vapor deposition (CVD) using N-containing carbon source, e.g., 1,3,5-triazine or pyridine, is a solvent-free technique, but scaling up is not straightforward [22,23]. It was found that samples prepared by CVD contain segregated domains of nitrogen dopants in the same sublattice. On the other hand, samples prepared by postsynthesis doping of pristine graphene exhibit a random distribution between sublattices [23].

In contrast to the "dry" approaches, $\mathrm{N}$-containing carbonaceous materials can be prepared by different conventional chemical means $[17,18]$. The wet chemical technologies usually require special pre-synthesized precursors or functionalisation, thermal activation, consumption of significant amount of solvents, etc., and sometimes, unavoidable by-products. In the present state of development, most of such chemical processes seem to be less controllable, as illustrated by the incomplete reaction of functional groups and the presence of precursor residues in the products. Finally, it is found that using chemical routes does not allow the distribution of $\mathrm{N}$ to be localized on the surface. This distribution plays a decisive role in the performance of carbon nano-material applications.

In this work thin films of multilayered graphene (MLGR) and highly oriented pyrolytic graphite (HOPG) were treated by low pressure RF $\mathrm{N}_{2}$ gas plasma, nominally at room temperature, and the amounts of implanted nitrogen and oxygen were determined by quantitative X-ray photoelectron spectroscopy (XPS). Their chemical bonding to the carbon matrix was also investigated in detail. A model was developed to calculate the surface enrichment of nitrogen in the top atomic monolayers of the graphene and HOPG samples. The validity of the assignments was tested for the first time by comparing the amount of reacted carbon with that required to satisfy the number of bonds of nitrogen and oxygen of the assigned chemical states. 


\section{Experimental}

\subsection{Samples}

Multi-layer graphene powder (MLGR), (consisting of about 6 atomic layers), obtained by mechanical exfoliation of high purity synthetic graphite (Aldrich, USA) [15], was disaggregated in carbon tetrachloride by ultrasonication. Thin films were prepared from this slurry by drop-wise deposition and drying onto a stainless steel holder ( $99 \mathrm{~mm})$ that was designed for the plasma treatment and the "in-situ" XPS measurements. A cylindrical piece of highly oriented (in the basal plane) pyrolytic graphite (HOPG) sample (NT-MDT Co., Russia) was fixed to an identical size sample holder and was used as reference material. HOPG is considered as a well defined bulk analog of MLGR. Before each experiment a thin $(<1 \mu \mathrm{m})$ top-layer was removed (by cleaving in air by detaching with ordinary adhesive tape), thereby exposing a completely pristine surface. This provides practically identical, contamination-free graphite surfaces for the modification reactions. The structural similarity (e.g., density of steps of crystal planes) is guaranteed by the purity and exact orientation of the HOPG crystal. The chemical similarity is ensured by removing several complete surface layers just before introducing the sample into the reaction (vacuum) chamber, thus avoiding any possible contamination from the environment.

\subsection{Treatments}

Plasma treatment was performed in the stainless steel sample preparation chamber of the XPS instrument (base pressure $<1 \cdot 10^{-4} \mathrm{~Pa}$ ). The high purity $\mathrm{N}_{2}(5 \mathrm{~N})$ flow of a few $\mathrm{ml} / \mathrm{min}$ (STP) was regulated by a bleeding valve that set the pressure to $5 \mathrm{~Pa}$. Constant RF power of $100 \mathrm{~W}$ at $13.56 \mathrm{MHz}$ was applied through a matching circuit to a stainless steel coil fixed inside the preparation chamber. The sample bias was set to $0 \mathrm{~V}$ (earthed) or to negative values of $50 \mathrm{~V}$, $100 \mathrm{~V}$ and $200 \mathrm{~V}$. Treatment time varied between 5 and $20 \mathrm{~min}$. After treatment the sample was transferred to the analysis chamber without exposing it to the ambient air.

\subsection{Characterization}

X-ray photoelectron spectra were recorded on a Kratos XSAM 800 spectrometer operating in fixed analyzer transmission mode, using $\mathrm{Mg} \mathrm{K \alpha _{1,2 }}(1253.6 \mathrm{eV})$ excitation. The pressure of the analysis chamber was lower than $1 \times 10^{-7} \mathrm{~Pa}$. Survey spectra were recorded in the kinetic 
energy range $150-1300 \mathrm{eV}$ in $0.5 \mathrm{eV}$ steps. Photoelectron lines of the main constituent elements, i.e., O1s, N1s and C1s, were recorded in $0.1 \mathrm{eV}$ steps with $1 \mathrm{~s}$ dwell time. Spectra were carefully referenced to the energy of the $\mathrm{C} 1 \mathrm{~s}$ line of the $\mathrm{sp}^{2}$ type graphitic carbon, set at $284.3 \pm 0.1 \mathrm{eV}$ binding energy (B.E.). The reliability of the bonding-state assignment for the $\mathrm{N}$-modified samples, based on the peak synthesis procedure has provoked tremendous discussion. Many publications have appeared in which fitting was carried out using components of largely different widths, incompatible with the resolution of the XPS instrument and settings. Based on our long standing practice in XPS, we applied here a rigorous procedure for fitting the complex peaks, thereby providing more reliable determinations of the position, i.e., the chemical shift, and also of the integrated intensity of the component peaks, which represent different bonding states. In accordance with our instrument setting, in this work a Gaussian-Lorentzian peak shape (G/L ratio 70/30) was used for peak decomposition of $\mathrm{N} 1 \mathrm{~s}, \mathrm{O} 1 \mathrm{~s}$ and for the reacted $\mathrm{C} 1 \mathrm{~s}$ lines. For the graphitic $\mathrm{C} 1 \mathrm{~s}$ component, an asymmetric shape was used, derived from the spectrum recorded on a pristine, contamination-free and oxygen-free HOPG. In addition, the peak-widths (full widths at half height) were strictly limited within $\pm 0.1 \mathrm{eV}$ : for $\mathrm{N} 1 \mathrm{~s}$ at $1.75 \mathrm{eV}, \mathrm{O} 1 \mathrm{~s}$ at $1.85 \mathrm{eV}$ reacted $\mathrm{C} 1 \mathrm{~s}$ at $1.95 \mathrm{eV}$ and graphitic $\mathrm{C} 1 \mathrm{~s}$ at $1.95 \mathrm{eV}$.

Quantitative analysis, based on peak area intensities after removal of the Shirley-type background, was performed by the Kratos Vision 2 and by the XPS MultiQuant programs [25-26], using the experimentally determined photo-ionization cross-section data of Evans et al. [27] and the asymmetry parameters of Reilman et al. [28]. In all cases, unless otherwise stated, the conventional infinitely thick layer model was employed, where all components are supposed to be homogeneously distributed within the sampling depth detected by XPS. Chemical shifts, representing different bonding states of the nitrogen and oxygen to the carbon matrix, and also of the reacted carbon, were evaluated by applying the above described accurate peak decomposition procedure using the Kratos Vision 2 software.

\section{Results and discussion}

\subsection{Chemical composition}

The overall surface composition for all pristine and treated samples was calculated using the conventional standard "infinitely thick homogeneous sample" model. 
Treatment time dependence of the $\mathrm{N}$ and $\mathrm{O}$ concentration in the MLGR sample. For a constant bias of $200 \mathrm{~V}$, Fig. 1 exhibits a sublinear increase of $\mathrm{N}$ with time. The figure shows that about 10 atomic $\%$ nitrogen is incorporated after $10 \mathrm{~min}$ treatment. To avoid 'overtreatment' of the surface by $\mathrm{N}$, the reaction time was limited to $10 \mathrm{~min}$ for all subsequent bias-dependent experiments.

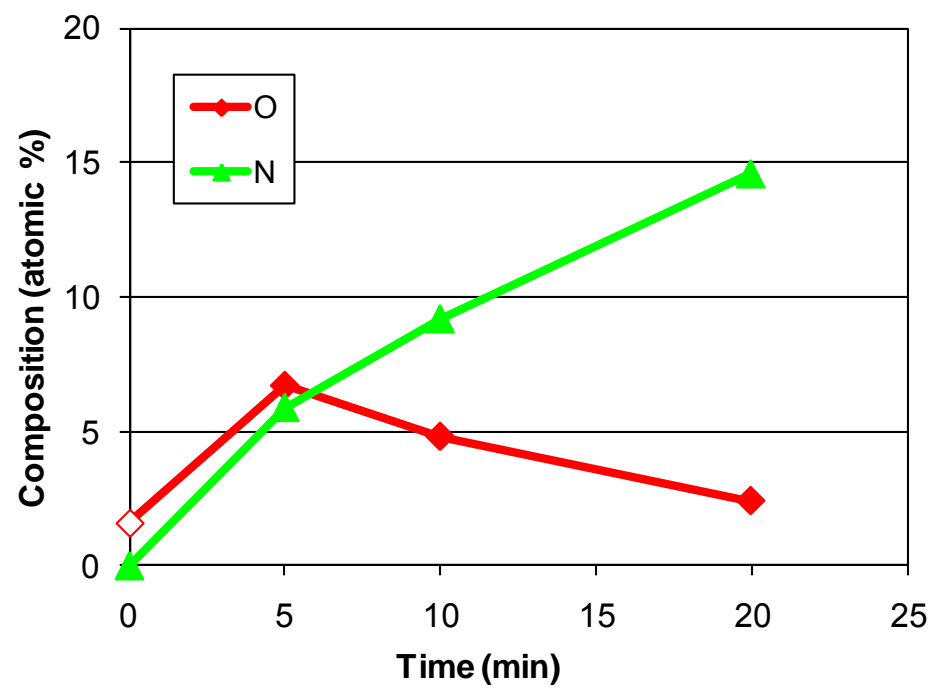

Fig. 1 Treatment time dependence of $N$ and $O$ of the MLGR sample, at constant $200 \mathrm{~V}$ bias.

The time-dependence of the oxygen contamination is not straightforward. The 7 atomic $\%$, measured after $5 \mathrm{~min}$, diminishes to about 2.5 atomic $\%$ at $20 \mathrm{~min}$. This led to the conclusion that the surface is contaminated with oxygen at the start of the treatment, and that the source of oxygen cannot therefore be the impurity content of the $\mathrm{N}_{2}$ flow. The trend implies that the main source of oxygen is the oxygen and water adsorbed on the chamber wall, which is desorbed by the plasma and slowly removed by the nitrogen flow.

Bias dependence: The N, C and O concentrations measured at selected increasing bias values are compared in Table 1. The bias-dependent alteration of the N-concentration is shown graphically in Fig. S1 of the Supplementary Information. The nitrogen concentration practically did not alter at $50 \mathrm{~V}$ with respect to $0 \mathrm{~V}$ but, as expected, increased steadily with the bias above $50 \mathrm{~V}$. On comparing the $\mathrm{N}$ concentration in MLGR with that in HOPG in Fig. S1 of the Supplementary Information it is notable that a significantly smaller amount of $\mathrm{N}$ was incorporated into $\mathrm{HOPG}$ at $0 \mathrm{~V}$ and $50 \mathrm{~V}$, while similar $\mathrm{N}$ concentrations were measured for both samples at $200 \mathrm{~V}$. 
From these results two conclusions could be drawn. The first is that at low $(\leq 50 \mathrm{~V})$ bias the covalent bonding of $\mathrm{N}$ is limited to the existing defect-sites of the samples. In this respect, the difference between the samples is obvious. The cleaved surface of the HOPG composed of extensive terraces with overall planar geometry may well be considered predominantly defectfree, as proved by STM and AFM measurements, and also supported by thermodynamic considerations [29]. Only the atoms at the step-edges of the terraces can be regarded as reactive defects. By contrast, the large number of edge atoms at the periphery of each multilayer graphene flake are regarded as defects, all able to react already at $\leq 50 \mathrm{~V}$ bias treatment, thus resulting in a higher $\mathrm{N}$-content.

Table 1 The overall surface compositions (atomic \%) of the untreated and plasma treated (10 min) samples, calculated by the "infinitely thick homogeneous sample" model

\begin{tabular}{|l|c|c|c|c|}
\hline \multicolumn{1}{|c|}{ Sample } & Bias (V) & O & C & N \\
\hline MLGR-0 & pristine & 1.6 & 98.4 & - \\
\hline MLGR-1 & 0 & 4.2 & 89.6 & 6.1 \\
\hline MLGR-2 & 50 & 4.0 & 90.3 & 5.7 \\
\hline MLGR-3 & 100 & 4.2 & 89.0 & 6.7 \\
\hline MLGR-4 & 200 & 4.8 & 85.9 & 9.3 \\
\hline HOPG-0 & pristine & 0.8 & 99.2 & - \\
\hline HOPG-1 & 0 & 5.0 & 91.2 & 3.8 \\
\hline HOPG-2 & 50 & 5.1 & 91.1 & 3.8 \\
\hline HOPG-3 & 100 & 5.6 & 88.9 & 5.5 \\
\hline HOPG-4 & 200 & 6.2 & 84.3 & 9.5 \\
\hline
\end{tabular}

The similar N content, found for the two samples at $200 \mathrm{~V}$, leads us to a second conclusion, namely that the $\mathrm{N}_{2}{ }^{+}$ions that bombard the surface of the samples are able to create a large number of reactive sites, including in-plane defects, thus equalizing the differences in apparent reactivity of MLGR and HOPG.

These conclusions are fully supported by the fairly high formation energy of defects, e.g., 7$8 \mathrm{eV}$ for carbon vacancies [29], and by the even higher energy needed to remove carbon atoms from an ideal graphite-like surface. Consequently, the $\mathrm{N}_{2}{ }^{+}$plasma ions accelerated at $50 \mathrm{~V}$ bias do not have sufficient energy to reach the so-called sputtering threshold for removing carbon atoms from the surface, i.e., to create reactive sites. 


\subsection{In-depth distribution of nitrogen}

It was known from our previous studies [11] that bias-initiated acceleration of the $\mathrm{N}_{2}{ }^{+}$ions towards the surface to be treated provides energy for subplantation of nitrogen below the outer atomic layers of the samples. The penetration depth of nitrogen depends on the negative bias voltage applied. The distribution of nitrogen beneath the surface can be estimated by the SRIM (Stopping and Range of Ions in Matter) program [30,31], which calculates the interaction of ions with matter based on Monte Carlo simulation method. As a result, the distribution of $\mathrm{N}$ below the surface, and hence the thickness of the modified layer can be calculated.

In the present experiments, relatively low values were deliberately selected to limit the modification to a few outer atomic layers of the samples, thus essentially preserving the original structure and the overall basic properties of the few atomic layer thick nano-carbon materials.

At the applied RF energy the overwhelming majority of the ionized species in the nitrogen plasma are the $\mathrm{N}_{2}{ }^{+}$ions $[32,33]$. When these molecular ions enter the surface they are neutralized and, if their kinetic energy is higher than the dissociation energy of $\mathrm{N}_{2}(9.8 \mathrm{eV})$, they also dissociate. The energy of the two nitrogen atoms is then, on average, half of the applied biasing energy [34,35]. Accordingly, at $50 \mathrm{~V}$ bias the appropriate input for the ion energy in the SRIM calculation is $25 \mathrm{eV}$, at $100 \mathrm{~V}$ bias it is $50 \mathrm{eV}$, and at $200 \mathrm{~V}$ bias $100 \mathrm{eV}$. The "stopping range calculation" program included not only the entire bias energy range used but also beyond, up to $200 \mathrm{eV}$. The results are depicted in Fig. 2. The projected energy range $\left(R_{p}\right)$ represents the mean depth below the surface of the MLGR sample at which the majority of ions of a given energy stop (lower curve). To account for the entire range of in-depth dispersion of the $\mathrm{N}$ ions beyond $\mathrm{R}_{\mathrm{p}}$, straggling must be added to $\mathrm{R}_{\mathrm{p}}$. This yields the upper curve in Fig. 2. 


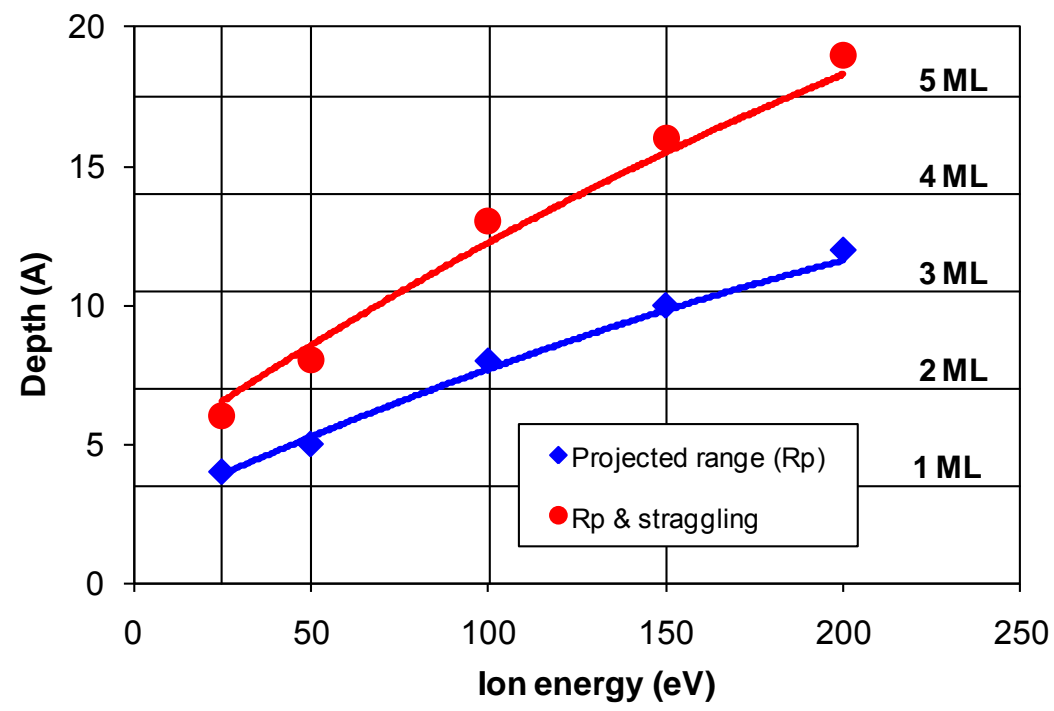

Fig. 2 The ion energy dependence of the projected energy range $\left(R_{p}\right)$ representing the mean depth at which the majority of ions of a given energy stop (lower curve) and $R_{p}$ with the added in-depth straggling (upper curve). Depth in monolayers $(M L)$ indicated at right hand scale.

These data show that the implanted nitrogen penetrates no deeper than $15 \AA$ into carbon materials, even at the highest applied bias of $200 \mathrm{~V}$, i.e., at $100 \mathrm{eV}$ ion energy. As a guide to the eye, the thickness of the atomic monolayers (MLs) is also indicated in the figure, assuming $3.35 \AA$ for the interlayer distance. Consequently, the modification is limited essentially to the first 2-4 monolayers for MLGR and also for HOPG in the applied bias range. In the case of the HOPG sample treated at $50 \mathrm{~V}$ bias, according to SRIM, the implanted nitrogen is situated in the first two monolayers of about $7 \AA$ thickness. The composition of this layer can be determined by applying the Layers-on-Plane model of the XPS MultiQuant program [25], on the basis of the measured C1s and N1s XPS intensity. The nitrogen concentration in this layer was found to be 23 atomic $\%$. This is more than three times higher than the values shown in Table 1, where the $\mathrm{N}$ concentration was determined by supposing it to be homogeneously distributed throughout the entire volume of the sample. These apparently contradictory results stem from the fact that the information depth of XPS ( $3 \lambda$, where $\lambda$ is the inelastic mean free path of N1s electrons) exceeds the implantation depth of nitrogen. The former is about $90 \AA$ in carbon, i.e., more than 25 graphene layers. From these results two conclusions may be drawn: $i$ ) the information depth of XPS can exceed the size of the nanoparticles, $i i)$ the $\mathrm{N}$ concentration in the top monolayers is significantly higher than in the average composition obtained directly by XPS. 
Accommodation of the high $\mathrm{N}$-content $(23$ at $\%)$ in the top two monolayers cannot be explained either by formation of pyridine, as commonly proposed, or by creation of pyrrole or diazine rings at the edges or defect-sites of the graphene sheets. It has, however, been amply demonstrated earlier that amorphous carbon nitride $\left(\mathrm{CN}_{\mathrm{x}}\right)$ films can be prepared under similar plasma activation conditions with $\mathrm{N}$ contents reaching 50 atomic $\%$, or even higher $[31,36]$. Recently, graphitic carbon nitride $\left(\mathrm{g}-\mathrm{C}_{3} \mathrm{~N}_{4}\right)$ has been successfully synthesized, and its structure was described as being composed of heptazine (tri-s-triazine) blocks [49-52]. In accordance with this finding, our interpretation of the high top-surface $\mathrm{N}$-content includes the formation of similar triazine clusters within the graphene plane, in addition to the pyridine, pyrrole, diazine and possible pyridazine rings at the edges of the graphene blocks [6].

\subsection{Chemical Structure}

The appreciable quantity of nitrogen incorporated into these carbon samples inevitably modifies the surface chemical structure of the ordered graphene network. This was monitored by the changes of the shape and shift of the high-resolution $\mathrm{C} 1 \mathrm{~s}, \mathrm{~N} 1 \mathrm{~s}$ and O1s XP spectra recorded in the MLGR and HOPG samples (Figs. 3-4). The chemical state of these elements in the MLGR and HOPG samples must be very similar, judging by the similar shape and shift of the otherwise complex peaks. During the plasma treatment the dominant change is the increase of the N1s peak and the simultaneous decrease of the C1s intensity with increasing bias. The $\mathrm{C}$ signal decreases with increasing bias, demonstrating that the implanted nitrogen incorporated in the top surface layers attenuates the carbon signal. The chemical states of the oxygen contamination, which entered accidentally during the plasma treatments, do not vary significantly, while its overall content changes, as shown in Table 1. 

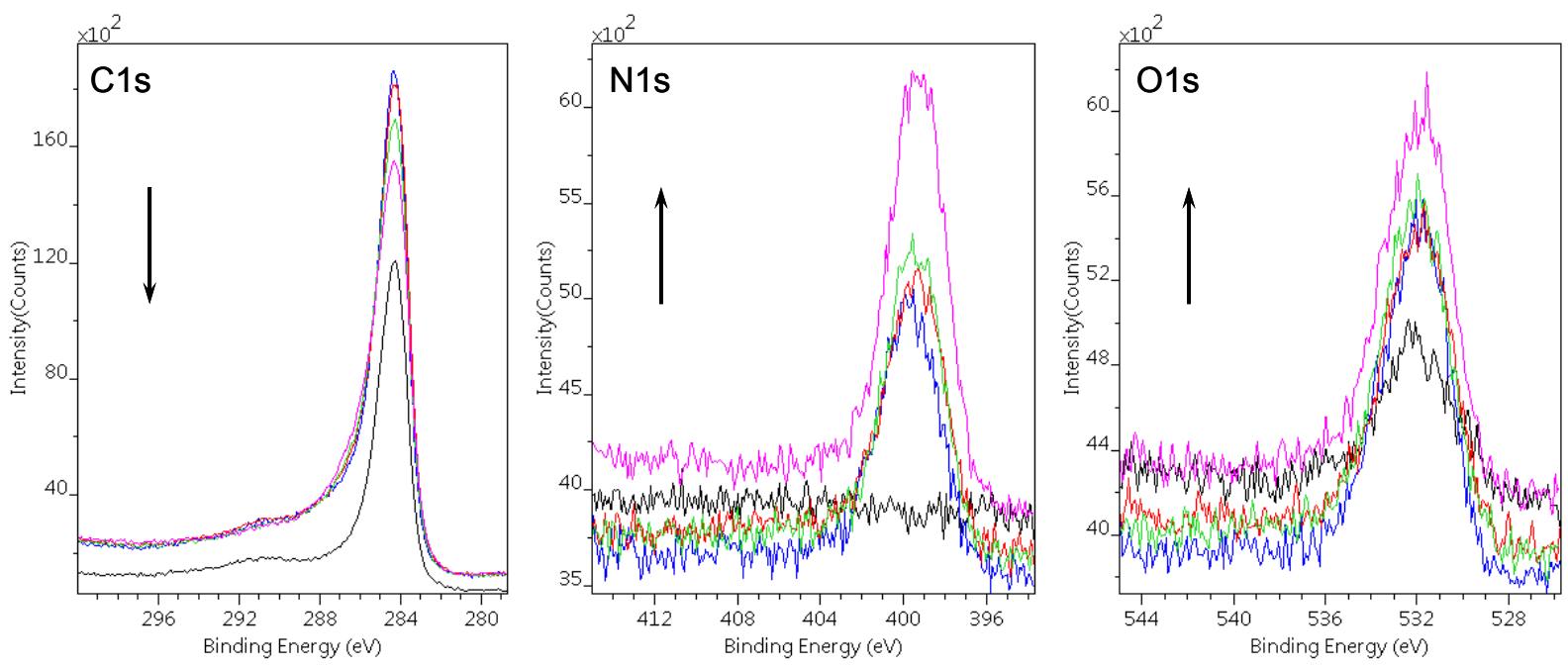

Fig. 3 High-resolution C1s, N1s and O1s XP spectra of the MLGR samples: untreated and treated at 0, 50,100 and $200 \mathrm{~V}$ bias. Arrows show direction of increasing bias.
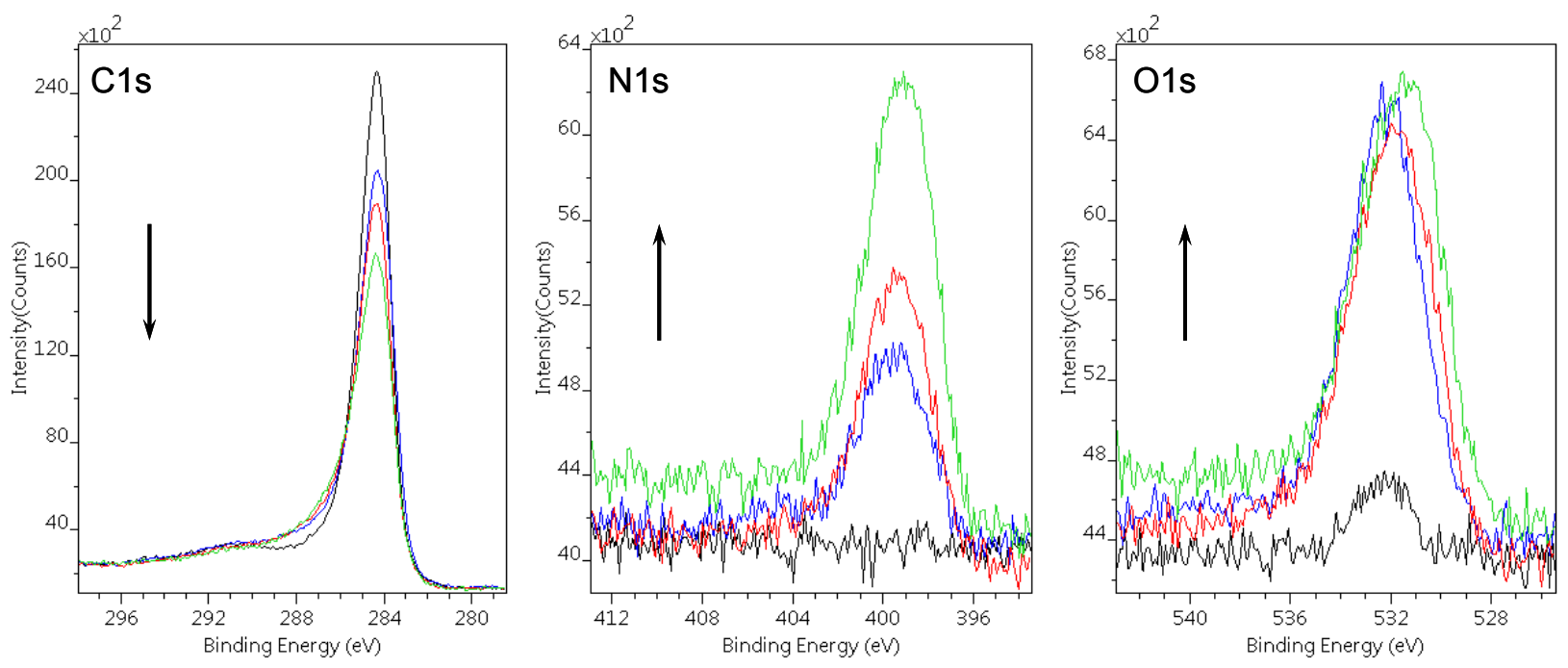

Fig. 4 High-resolution C1s, N1s and O1s XP spectra of the HOPG samples: untreated and treated at 50, 100 and 200 V bias. Arrows show direction of increasing bias.

Chemical state of nitrogen: High-resolution XP spectra of the N1s energy region for the representative MLGR and HOPG samples treated at $200 \mathrm{~V}$ bias are shown in Fig. 5. The broad peak envelopes clearly demonstrate that the nitrogen atoms are situated in different chemical environments. On decomposing the peaks into Gauss-Lorentz shaped components of half-width $1.75 \mathrm{eV}$, corresponding to single chemical states at the applied resolution, three different N1s chemical shifts (denoted hereafter as N1, N2 and N3) were found in all samples. The components at $398.3 \pm 0.2 \mathrm{eV}, 399.7 \pm 0.2 \mathrm{eV}$ and $400.9 \pm 0.2 \mathrm{eV}$ correspond to at least 
three different $\mathrm{N}-\mathrm{C}$ bond environments. For all treated samples the results of the peak decomposition are shown in Fig. S2 in the Supplementary Information. The relative intensity of these component peaks is somewhat different in each treatment. Their assignments to certain chemical bonding states have been abundantly discussed in numerous experimental works devoted to synthesis of various $\mathrm{CN}_{\mathrm{x}}$ type materials [36-47], to nitrogen-containing diamond-like carbon (DLC) type coatings [11,31,35] and to carbon based macromolecular or polymeric substances $[47,48]$. The current controversy was broadly discussed in [36-39,49] and is also presented in Fig. 7. Taking into account these data and our earlier findings, we assign the $\mathrm{N} 1$ peak component at $398.3 \mathrm{eV}$ to $\mathrm{C}=\mathrm{N}-\mathrm{C}$ type chemical environment, where the $\mathrm{sp}^{2}$ nitrogen is bonded to two $\mathrm{sp}^{2}$ type carbons, as in pyridine [35,45-46]. The $\mathrm{N} 2$ component at $399.7 \mathrm{eV}$ is assigned to $\mathrm{sp}^{2} \mathrm{~N}$ in the pyrrole, diazine- and triazine-type ring structure [49]. We attribute the $\mathrm{N} 3$ type $\mathrm{N}$ at $400.9 \mathrm{eV}$ to $\mathrm{N}$ substituting carbon in graphite-like environment $[35,12]$. These assignments are summarized in Table 2.

Importantly, the shift of the different chemical states of nitrogen does not alter with the applied bias, but their relative intensity does change, as depicted in Fig. 6. The increase of Ncontent with bias can be related to the increase of $\mathrm{N} 1$ and $\mathrm{N} 2$ components, while the $\mathrm{N} 3$ component did not alter appreciably.

Table 2 Assignment of N1s components of the plasma treated MLGR and HOPG

\begin{tabular}{|c|c|l|}
\hline Component & Energy $(\boldsymbol{e V})$ & \multicolumn{2}{|c|}{ Assignment } \\
\hline $\mathrm{N} 1$ & $398.3 \pm 0.2$ & $\mathrm{sp}^{2} \mathrm{~N}$ in pyridine type ring \\
\hline $\mathrm{N} 2$ & $399.7 \pm 0.2$ & $\begin{array}{l}\mathrm{sp}^{2} \mathrm{~N} \text { in pyrrole, diazine or } \\
\text { triazine type ring structure }\end{array}$ \\
\hline $\mathrm{N} 3$ & $400.9 \pm 0.2$ & $\begin{array}{l}\mathrm{N} \text { substituting } \mathrm{C} \text { in graphite } \\
\text { plane }\end{array}$ \\
\hline
\end{tabular}



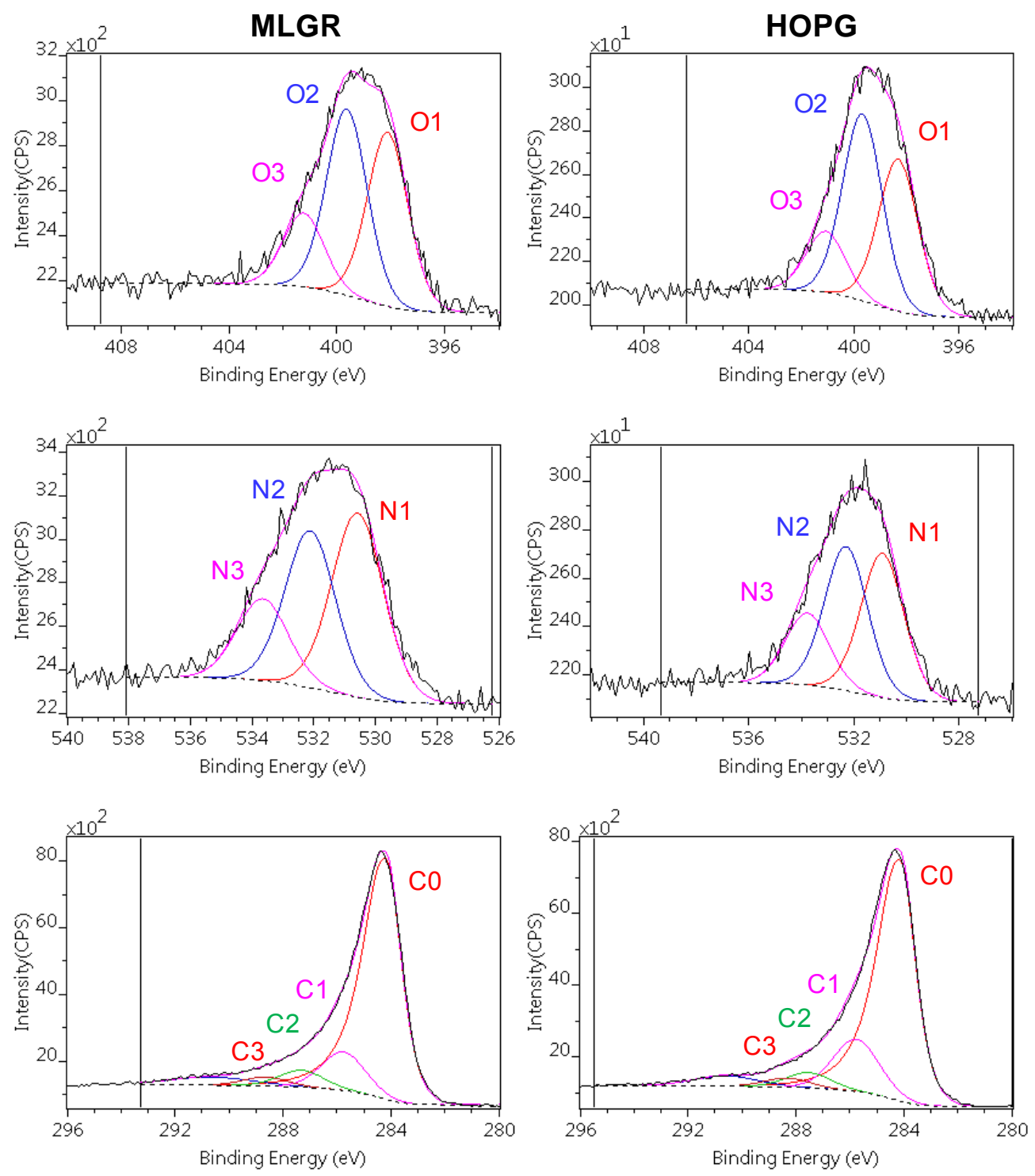

Fig. 5 Decomposition of the high-resolution XP spectra of the N1s, O1s and C1s regions for the MLGR and HOPG samples treated at 200 V bias. Labels are explained in Tables 2-4.

Chemical state of oxygen: The broad O1 peak envelope in the plasma treated MLGR and HOPG can also be fitted with 3 components of identical width. The bonding state of oxygen was analyzed by the shifts of the three components (O1, O2, O3) shown in Fig. 6 and for all samples in Fig. S3 of the Supplementary Information. For the 50-200 V plasma treatments the chemical states of oxygen remain the same for both types of sample, and only their relative intensity changes (Fig. 6). The assignment of these shifts given in Table 3 was determined on the basis of related references, summarized in Fig. 7 and in Table S1 of the Supplementary Information. The epoxy and part of the $\mathrm{OH}$ groups are believed to be attached on top of the graphene planes, while all the other bonding configurations are located predominantly on the 
edges of the planes or attached to the carbon atoms surrounding the in-plane defect sites around carbon vacancies $[14,50]$.

No significant bias dependence of the $\mathrm{O} 2$ and $\mathrm{O} 3$ components was observed (Fig. 8); only the O1 component, i.e., the oxygen double-bonded to carbon, shows a relative increase.

MLGR
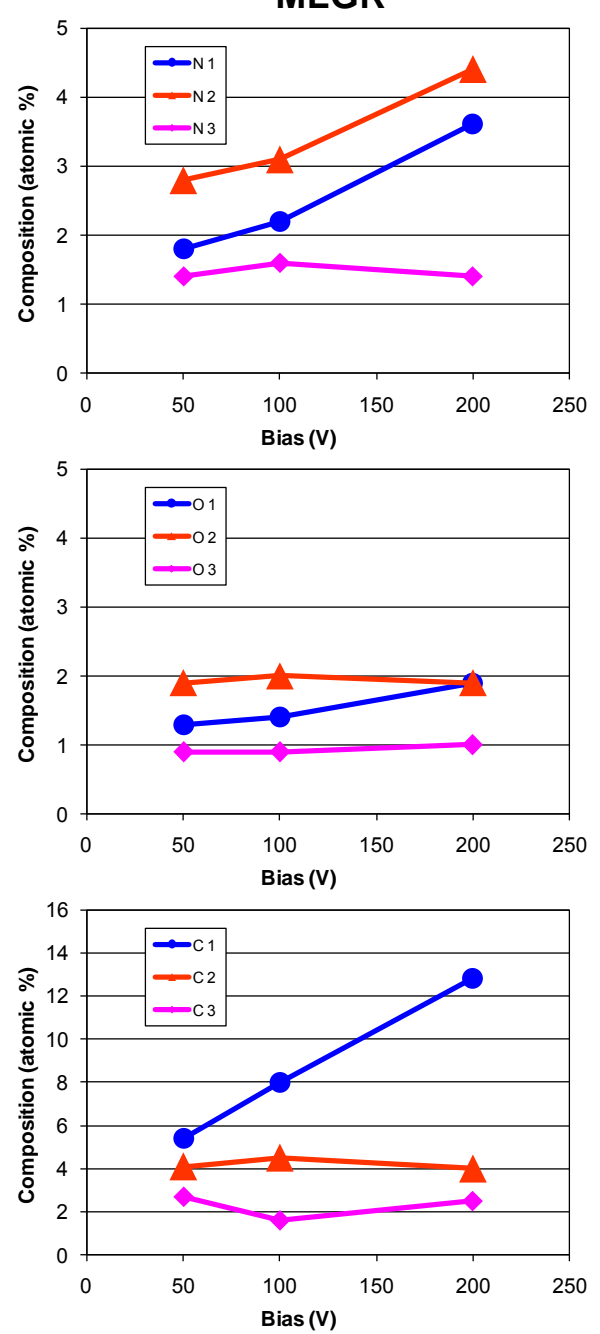

HOPG
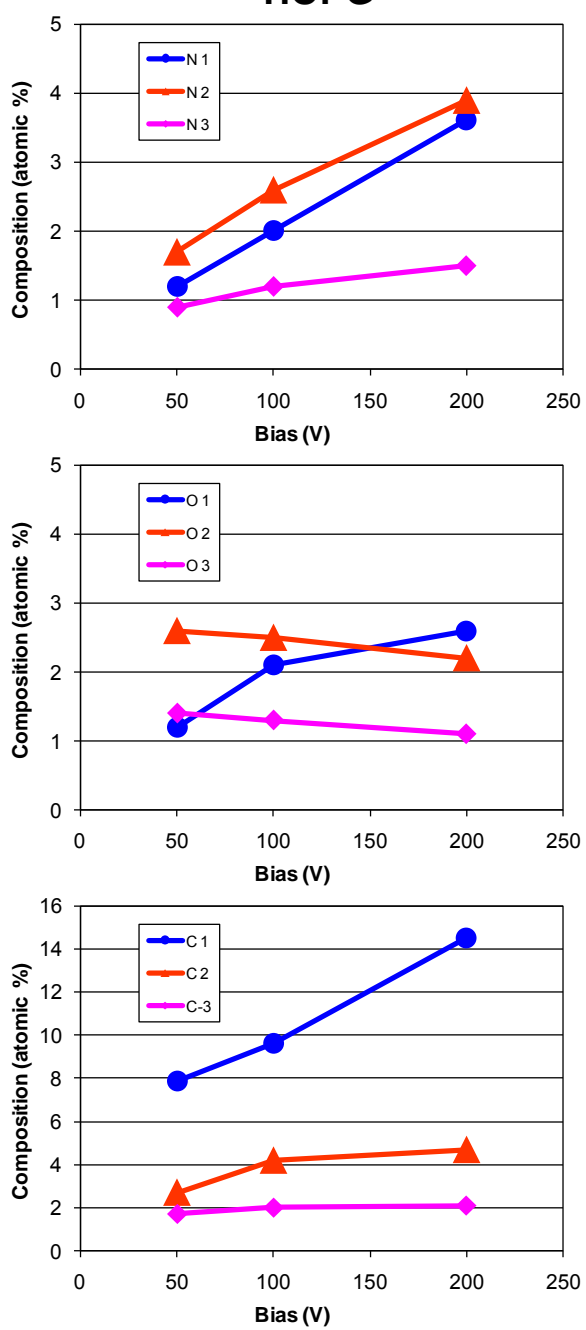

Fig. 6 Change in concentration of the N1s, Ols and Cls peak components of the MLGR and HOPG samples treated at increasing bias. Labels are explained in Tables 2-4.

Chemical state of carbon: As shown in Figs. 3-4, the shapes of the C1s lines of the MLGR and HOPG samples are complex and asymmetric, and they also display a shake-up type satellite, characteristic of all graphitic carbons [40,41]. Numerous attempts have been made to fit such spectral envelopes with individual peaks assigned to predefined chemical bonding states of the carbon to nitrogen and oxygen atoms [40,41,47-49,53-55]. 
Table 3 Assignment of Ols components of the plasma treated MLGR and HOPG

\begin{tabular}{|c|c|c|c|}
\hline Component & Energy $(e V)$ & \multicolumn{2}{|c|}{ Assignment } \\
\hline O1 & $530.6 \pm 0.3$ & O in carbonyl group & $\bar{c}=0$ \\
\hline $\mathrm{O} 2$ & $532.0 \pm 0.2$ & $\begin{array}{l}\mathrm{O} \text { in ether and epoxy } \\
\mathrm{OH} \text { in alcohol } \\
\mathrm{C}=\mathrm{O} \text { in ester }\end{array}$ & $\begin{array}{cc}\mathrm{C}-\mathrm{O}-\mathrm{c} & \mathrm{O} \\
\mathrm{C}-\mathrm{OH} & \mathrm{c}-\mathrm{c} \\
& \mathrm{O}^{*} \\
-\mathrm{C}-\mathrm{O}-\mathrm{c}\end{array}$ \\
\hline $\mathrm{O} 3$ & $533.4 \pm 0.3$ & $\begin{array}{l}\mathrm{C}-\mathrm{O}-\mathrm{C} \text { in ester } \\
\mathrm{OH} \text { in carboxyl }\end{array}$ & 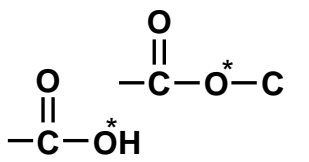 \\
\hline
\end{tabular}

Chemical state alterations of the C1s spectra should be determined and treated with care, taking into account the various sources of uncertainty that are mostly overlooked in the evaluation of published data. The reliability of the bonding-state assignment for the Nmodified samples, based on the conventional peak synthesis procedure, can be problematic. The complexity caused by the several different nitrogen and oxygen bonds to the carbon atoms should be considered. Moreover, interaction among these moieties may also alter the charge redistribution [6]. Thus the chemical shifts of all the bonding types may be interconnected, i.e., not defined precisely, thereby introducing a degree of uncertainty into the C1s peak assignments.

The assignment of the $\mathrm{C} 1 \mathrm{~s}$ peak components (also of N1s and O1s) is based on an assumed analogy with macromolecular or polymer substances of well-defined structure measured at similar conditions. A large number of examples of such compounds are reported in the literature. [12,56,57]. Here we also incorporated published data on surface treated carbonaceous materials containing $\mathrm{N}$ and $\mathrm{O}$ atoms given in Table $\mathrm{S} 1$ in the Supplementary Information.

Before discussing a recently published set of data [5,14,40,41,47,48,53-57] of surface treated nanocarbon materials, depicted in Fig. 7 (and in Table 1 in the Supplementary Information), several problems associated with the published peak-synthesis procedure and the following assignments have to be emphasized. First of all, the signal from the unreacted aromatic carbon network is asymmetric, a fact that is sometimes neglected in the synthesis procedure. This, however, will affect both the position and the intensity of the $\mathrm{C}-\mathrm{N}$ and $\mathrm{C}-\mathrm{O}$ peak components, especially those closest in energy to the unreacted $\mathrm{C}-\mathrm{C}$ component. 
In the applied experimental conditions, using non-monochromatic $\mathrm{Mg} \mathrm{K} \alpha_{1,2}$ or $\mathrm{Al} \mathrm{K} \alpha_{1,2}$ excitation, the FWHM (full width at half maximum) of the symmetric C1s components of the $\mathrm{C}-\mathrm{N}$ and $\mathrm{C}-\mathrm{O}$ bonds are in the range $1.8-1.9 \mathrm{eV}$. Consequently, if two or more peaks are positioned closer than $0.9 \mathrm{eV}$, they will overlap significantly, making the determination of their position and intensity unreliable. Peak decomposition with different FWHM values is also applied without explanation.

Analysis of the chemical shifts of these published data (Fig. 7) shows that the scatter in the binding energy values is substantially larger than the usual expected accuracy of peak position determination $( \pm 0.2-0.3 \mathrm{eV})$. Overlapping of the data related to different chemical states indicates possible errors of assignment.
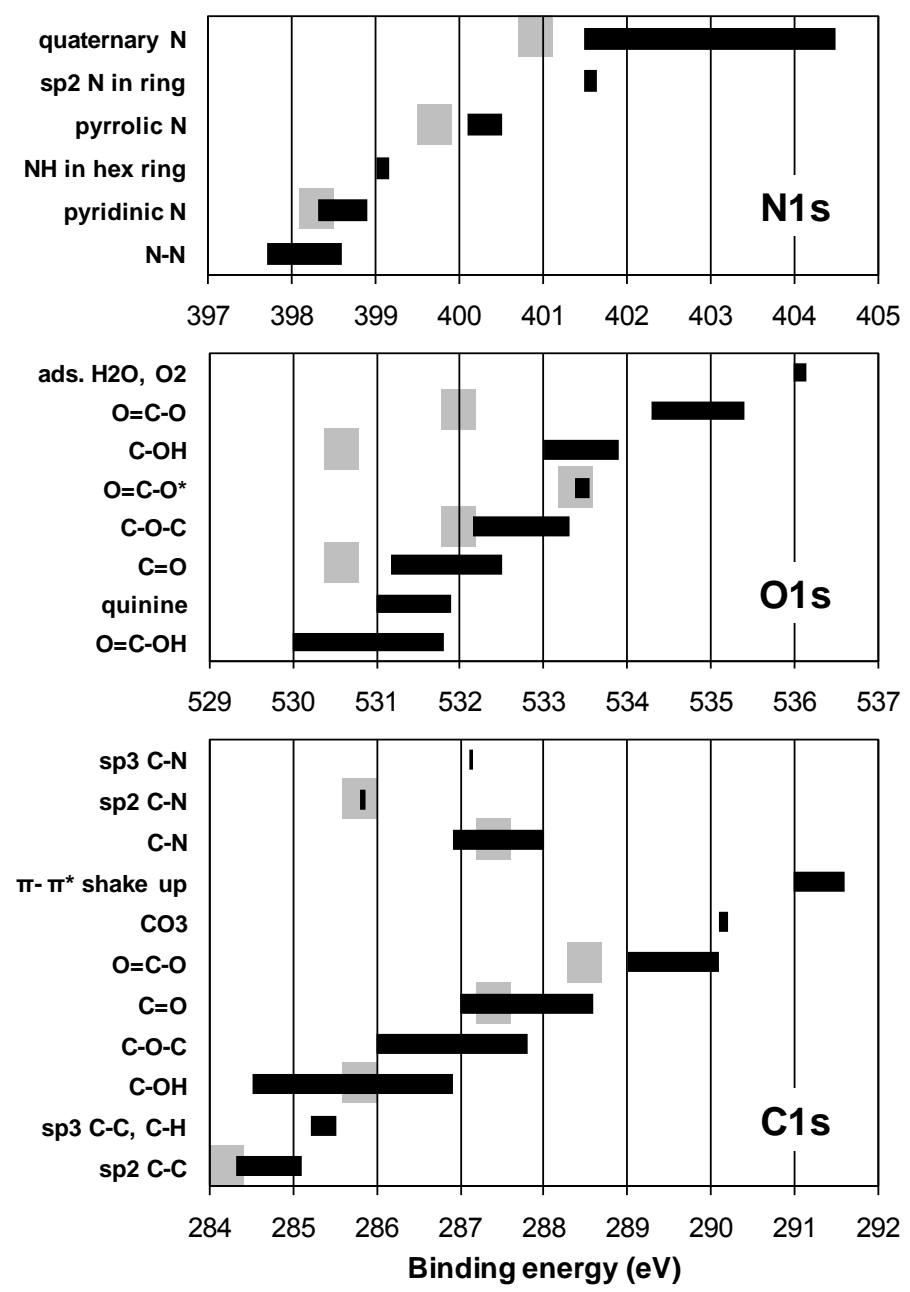

Fig. 7 Binding energy values and assignation of the $N 1 s, O 1 s$ and $C 1$ s peaks recently published for the variously treated nanocarbon materials [5,14,40,41,47,48,53-57] (numerical data in Table S1 in the Supplementary Information). Data from this work are indicated by grey boxes. 
The closeness of peak positions (Table S1) supposes significant overlapping of several peaks, assigned to different $\mathrm{C}-\mathrm{N}$ and $\mathrm{C}-\mathrm{O}$ chemical states. A further point in this respect may be the secondary effect of mutual interactions among the different hetero-atom containing clusters separated by only one or a few carbon atoms in the matrix. Such an effect is not reflected in the chemical shift of the model compounds.

Here we have attempted to decompose the C1s peak of MLGR and HOPG samples, avoiding, or, at least, taking into account the above described pitfalls. To fit the peak of the unaffected carbon matrix we used the asymmetric line shape that was recorded on the pristine HOPG sample. We fitted the peak envelope using three additional components of identical G/L shape and width of $1.95 \pm 0.05 \mathrm{eV}$ for MLGR and $1.85 \pm 0.05 \mathrm{eV}$ for HOPG.

The good fit obtained for the $\mathrm{C} 1 \mathrm{~s}$ lines, shown in Fig. 5, implies that the shifts induced by three different $\mathrm{N}-\mathrm{C}$ and three different $\mathrm{O}-\mathrm{C}$ bonds are similar (Fig. 7). The suggested assignations of the various $\mathrm{C} 1 \mathrm{~s}$ components are listed in Table 4.

Table 4 Assignment of Cls components of all plasma treated MLGR and HOPG samples

\begin{tabular}{|c|c|l|}
\hline Component & Energy $(\boldsymbol{e V})$ & \multicolumn{1}{c|}{ Assignment } \\
\hline $\mathrm{C} 0$ & $284.3 \pm 0.1$ & $\mathrm{sp}^{2} \mathrm{C}$ in graphite/graphene plane \\
\hline $\mathrm{C} 1$ & $285.8 \pm 0.2$ & $\begin{array}{l}\mathrm{C}-\mathrm{N} \text { bond in pyridine ring or amine } \\
\mathrm{C} \text { in hydroxyl, ether or epoxy bond }\end{array}$ \\
\hline $\mathrm{C} 2$ & $287.4 \pm 0.2$ & $\begin{array}{l}\mathrm{C}-\mathrm{N} \text { bond in graphite plane } \\
\mathrm{C} \text { in carbonyl bond }\end{array}$ \\
\hline $\mathrm{C} 3$ & $288.5 \pm 0.2$ & $\begin{array}{l}\mathrm{C} \text { in amide bond } \\
\mathrm{C} \text { in carboxyl or ester bond }\end{array}$ \\
\hline
\end{tabular}

Having determined the amount of the chemical state, we may try to compare the sum of reacted carbon components to that required by the covalently bonded $\mathrm{N}$ and $\mathrm{O}$, taking into account their assigned bonding states. 

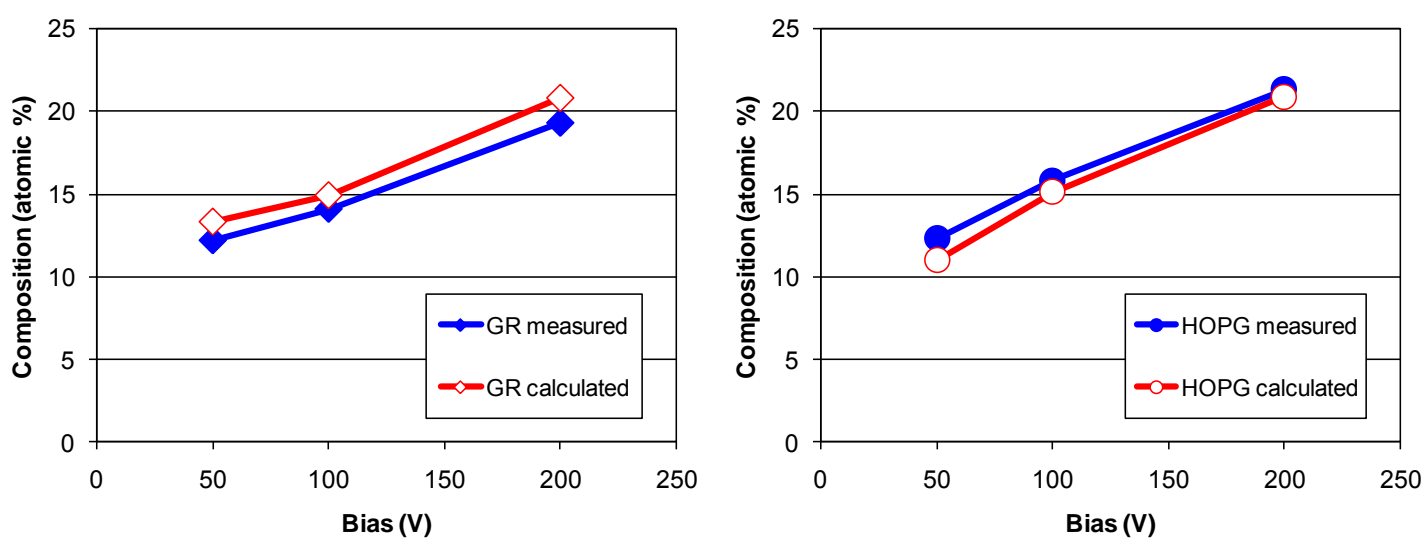

Fig. 8 Comparison of the sum of reacted carbon components to that required by the covalently bonded $N$ and $O$, taking into account their assigned bonding states.

As shown in Table 2, the N1 and the N2 nitrogens are bonded to two neighboring carbons. Consequently, since the acquired carbon satisfies the bonding, the amount of N1 and N2 must be multiplied by two. Although the N3 nitrogens have three carbon neighbors, their amount is not counted, suggesting that N3 does not alter measurably the electron density, because its non-bonding electron pair takes part in the conjugated electron structure of the graphite plane. Therefore the chemical shift of the three neighboring carbon atoms is not altered, i.e., it coincides with the $\mathrm{sp}^{2}$ type graphitic component.

According to Table 3, the $\mathrm{O} 1$ type oxygen is bonded to one carbon. The $\mathrm{O} 2$ is connected to one carbon in an ester bond, and to two carbons in ether or epoxy bonds. The $\mathrm{O} 3$ component is bonded to a second carbon in esters, but no additional carbon is required in carboxylic acids. (We suppose that $\mathrm{O} 2$ and $\mathrm{O} 3$ are all bonded to one carbon.)

In Fig. 8 the sum of the measured reacted carbon is compared with the sum of the carbon required for $\mathrm{N}$ and $\mathrm{O}$ hetero-atoms calculated as described above. In spite of the possible experimental errors and the mentioned omission in the definition of the applied coefficients, the greatest difference does not exceed $12 \%$. This reasonable agreement justifies the validity of our assignments of the chemical states, indicated in Fig. 7, together with reference data. To the best of our knowledge, this is the first attempt to verify the assignments of the chemical states on functionalized nanocarbon surfaces by quantitative XPS data.

\section{Conclusions}

- It is demonstrated that the surface of MLGR and HOPG can be conveniently modified using RF plasma activated low pressure nitrogen. The amount of nitrogen can be tuned — in the range $4-10$ atomic $\%$ with 10 min treatment — by varying the negative sample 
bias between $50 \mathrm{~V}$ and $200 \mathrm{~V}$. The implanted nitrogen is incorporated in the top 1-4 atomic monolayers (5-15 $\AA$ ) of the samples.

- Only a small amount of $\mathrm{N}$ could be incorporated at $\leq 50 \mathrm{~V}$ bias into HOPG, the surface of which is predominantly defect-free with overall planar geometry, while in MLGR treated under the same conditions a larger amount of $\mathrm{N}$ was found. This difference is related to the higher number of reactive defect sites in MLGR than in HOPG, taking into account the large number of atoms at the edges of the nano-carbon sheets in the former sample. At $200 \mathrm{~V}$, formation of multiple defects equalizes the difference in reactivity between MLGR and HOPG.

- The three different chemical bonding states of the nitrogen were defined for all treated samples and assigned to pyridine-type (N1) and to N in pyrrole-type ring structures (N2), and to $\mathrm{N}$ substituting carbon in a graphite-like environment (N3). The N1 and N2 components increase significantly with increasing applied bias. The oxygen impurity also appeared in three chemical states, and was tentatively assigned respectively to carbonyl (O1), to ether, epoxy and $\mathrm{C}=\mathrm{O}$ in ester and anhydride $(\mathrm{O} 2)$, and to $-\mathrm{O}-\mathrm{C}=$ in ester and anhydride and carboxyl (O3) chemical environments.

- Bonding-state assignment, based on the published peak synthesis procedures of the $\mathrm{C} 1 \mathrm{~s}$ peak envelope, is critically discussed, indicating the various sources of uncertainty introduced by the complexity of the systems studied, which are frequently overlooked in the published literature. Efforts were made to determine the $\mathrm{C}-\mathrm{N}$ and $\mathrm{C}-\mathrm{O}$ bonding states by carefully constructing the $\mathrm{C} 1 \mathrm{~s}$ peak envelopes from the natural asymmetric line shape for fitting the unreacted component recorded on the pristine HOPG and MLGR samples. Assignment of the peaks was made with caution, pointing out the possible uncertainties.

- The reasonable agreement found by comparing the amount of reacted carbon with that required by the $\mathrm{N}$ and $\mathrm{O}$ atoms validates our assignment of the chemical states generated by nitrogen plasma modification.

- To our knowledge this is the first attempt to verify the assignments of the chemical states on functionalized nanocarbon surfaces by quantitative XPS data. 


\section{Acknowledgement}

This work was sponsored by the National Scientific Research Fund (OTKA) through the project No. K-109558. Technical assistance of L. Gulyás is acknowledged.

\section{References}

1. C. Soldano, A. Mahmood, E. Dujardin, Production, properties and potential of graphene, Carbon 48 (2010) 2127-2150.

2. Y.H. Hu, H. Wang, B. Hu, Thinnest Two-Dimensional Nanomaterial-Graphene for Solar Energy, ChemSusChem 3 ( 2010) 782-796.

3. T. Kuila, S. Bose, A.K. Mishra, P. Khanra, N.H. Kim, J.H. Lee, Chemical functionalization of graphene and its applications, Progress in Materials Science 57 (2012) 1061-1105.

4. L. Feng, L. Wu, X. Qu, New Horizons for Diagnostics and Therapeutic Applications of Graphene and Graphene Oxide, Advanced Materials 25 (2013) 168-186.

5. Y. Wang, Y. Shao, D.W. Matson, J. Li, Y. Lin, Nitrogen-Doped Graphene and Its Application in Electrochemical Biosensing, ACS Nano 4 (2010) 1790-1798.

6. Y. Yamada, J. Kim, S. Matsuo, S. Sato, Nitrogen-containing graphene analyzed by X-ray photoelectron spectroscopy, Carbon 70 (2014) 59-74;

DOI: 10.1016/j.carbon.2013.12.061.

7. A. Tóth, K.V. Voitko, O. Bakalinska, G.P. Prykhod'ko, I. Bertóti, V.M. Gun'ko, K. László: Morphology and adsorption properties of chemically modified MWCNT probed by nitrogen, n-propane and water vapor. Carbon, 50(2), 577-585 (2012)

8. R.L.D. Whitby, V.M. Gun'ko, A. Korobeinyk, R. Busquets, A.B. Cundy, K. László et al., Driving Forces of Conformational Changes in Single-Layer Graphene Oxide, ACS Nano 6 (2012) 3967-3973.

9. T. Ramanathan, A.A. Abdala, S. Stankovich, D.A. Dikin, M. Herrera-Alonso, R.D. Piner et al., Functionalized graphene sheets for polymer nanocomposites, Nat. Nanotechnol. 3 (2008) 327-331; DOI:10.1038/nnano.2008.96 .

10. T. Kuila, S. Bhadra, D.H. Yao, N.H. Kim, S. Bose, J.H. Lee, Recent advances in graphene based polymer composites, Progress in Polymer Science 35 (2010) 1350-1375. 
11. I. Bertóti, I. Mohai, M. Mohai, J. Szépvölgyi, Surface modification of multi-wall carbon nanotubes by nitrogen attachment, Diamond Relat. Mater. 20 (2011) 965-968;

DOI: 10.1016/j.diamond.2011.05.011.

12. J.M. Englert, C. Dotzer, G.A. Yang, M. Schmid, C. Papp, J.M. Gottfried, et al., Covalent bulk functionalization of graphene, Nat. Chem. 3 (2011) 279-286; DOI: 10.1038/NCHEM.1010.

13. J.P. Boutique, J.J. Verbist, J.G. Fripiat, J. Delhalle, G. Pfister-Guillouzo, G.J. Ashwell, 3,5,11,13-Tetraazacycl[3.3.3]azine: Theoretical (ab Initio) and Experimental (X-ray and Ultraviolet Photoelectron Spectroscopy) Studies of the Electronic Structure, J. Am. Chem. Soc. 106 (1984) 4374-4378; DOI: 10.1021/ja00328a012.

14. I-S. Byun, W. Kim, D.W. Boukhvalov, I. Hwang, J.W. Son, G. Oh, et al., Electrical control of nanoscale chemical modification in graphene, NPG Asia Materials 6 (2014) e102-107; DOI: 10.1038/am.2014.24.

15. B. Guo, Q. Liu, E. Chen, H. Zhu, L. Fang, J.R. Gong, Controllable N-Doping of Graphene Nano Lett. 10 (2010) 4975-4980.

16. N.A. Kumar, H. Nolan, N. McEvoy, E. Rezvani, R.L. Doyle, M.E.G. Lyons, et al., Plasma-assisted simultaneous reduction and nitrogen doping of graphene oxide nanosheets, J. Mater. Chem. A 1 (2013) 4431-4435.

17. H. Wang, T. Maiyalagan, X. Wang, Review on Recent Progress in Nitrogen-Doped Graphene: Synthesis, Characterization, and Its Potential Applications, ACS Catal. 2 (2012) 781-794.

18. Y. Lu, Y. Huang, M. Zhang, Y.J. Chen, Nitrogen-doped graphene materials for supercapacitor applications, Nanosci. Nanotechnol. 14 (2014) 1134-1144.

19. X. Li , H. Wang, J.T. Robinson, H. Sanchez, G. Diankov, H. Dai, Simultaneous Nitrogen Doping and Reduction of Graphene Oxide, J. Am. Chem. Soc. 131 (2009) $15939-15944$.

20. D. Geng, Y. Chen, Y. Chen, Y. Li, R. Li, X. Sun, et al., High oxygen-reduction activity and durability of nitrogen-doped graphene, Energy Environ. Sci. 4 (2011), 760-764.

21. L. Wang, Z. Sofer, J. Luxa, M. Pumera, Nitrogen doped graphene: influence of precursors and conditions of the synthesis, J. Mater. Chem. C 2 (2014) 2887-2893. 
22. Y. Lu, S. Lo, J. Lin, W. Zhang, J. Lu, F. Liu, et al., Nitrogen-Doped Graphene Sheets Grown by Chemical Vapor Deposition: Synthesis and Influence of Nitrogen Impurities on Carrier Transport, ACS Nano 7 (2013) 6522-6532.

23. A. Zabet-Khosousi, L. Zhao, L. Pálová, M.S. Hybertsen, D.R. Reichman, A.N. Pasupathy, et al., Segregation of Sublattice Domains in Nitrogen-Doped Graphene, J. Am. Chem. Soc. 136 (2014) 1391-1397.

24. P. Kun, F. Weber, C. Balázsi, Preparation and examination of multilayer graphene nanosheets by exfoliation of graphite in high efficient attritor mill, Cent. Eur. J. Chem. 9 (2011) 47-51; DOI: 10.2478/s11532-010-0137-5.

25. M. Mohai, XPS MultiQuant: Multimodel XPS Quantification Software, Surf. Interface Anal. 36 (2004) 828-832; DOI: 10.1002/sia.1775; http://aki.ttk.mta.hu/XMQpages/XMQhome.htm.

26. M. Mohai, I. Bertóti, Calculation of Overlayer Thickness on Curved Surfaces Based on XPS Intensities, Surf. Interface Anal. 36 (2004) 805-808; DOI: 10.1002/sia.1769.

27. S. Evans, R.G. Pritchard, J.M. Thomas, Relative Differential Subshell Photoionization Cross-sections $(\mathrm{Mg} \mathrm{K} \alpha)$ from Lithium to Uranium, J. Electron Spectrosc. Relat. Phenom. 14 (1978) 341-358.

28. R.F. Reilman, A. Msezane, S.T. Manson, Relative Intensities in Photoelectron Spectroscopy of Atoms and Molecules, J. Electron Spectrosc. Relat. Phenom. 8 (1976) 389-394.

29. M. Batzill, The surface science of graphene: Metal interfaces, CVD synthesis, nanoribbons, chemical modifications, and defects, Surface Science Reports 67 (2012) $83-115$.

30. J.F. Ziegler, M.D. Ziegler, J.P. Biersack, Stopping and Range of Ions in Matter (SRIM 2006), 2006; htpp://www.SRIM.org.

31. I. Bertóti, A. Tóth, M. Mohai, T. Ujvári, Comparison of Composition and Bonding States of Constituents in $\mathrm{CN}_{\mathrm{x}}$ Layers Prepared by DC Plasma and Magnetron Sputtering, Surf. Interface Anal. 30 (2000) 538-543.

32. B. Fritsche, T. Chevolleau, J. Kourtev, A. Kolitsch, W. Möller, Plasma diagnostic of an RF magnetron Ar/ $\mathrm{N}_{2}$ discharge, Vacuum 69 (2002) 139-145. 
33. A. Qayyum, S. Zeb, S. Ali, A. Waheed, M. Zakaullah, Optical emission spectroscopy of abnormal glow region in nitrogen plasma, Plasma Chemistry and Plasma Processing, 25, (2005) 551-564.

34. I. Bertóti, Characterization of nitride coatings by XPS, Surf. Coat. Technol. 151-152 (2002) 194-203.

35. W.T. Zheng, K.Z. Xing, N. Hellgren, M. Lögdlund, Å. Johansson, U. Gelivs et al., Nitrogen 1s electron binding energy assignment in carbon nitride thin films with different structures, J. Electron Spectrosc. Relat. Phenom. 87 (1997) 45-49; DOI: 10.1016/S03682048(97)00083-2.

36. A. Baker, P. Hammer, A study of the chemical bonding and microstructure of ion beamdeposited $\mathrm{CN}_{\mathrm{x}}$ films including an XPS C 1s peak simulation, Surf. Interface Anal. 25 (1997) 301-314.

37. S. Souto, M. Pickholz, M.C. dos Santos, F. Alvarez, Electronic structure of nitrogencarbon alloys $\left(\mathrm{a}-\mathrm{CN}_{\mathrm{x}}\right)$ determined by photoelectron spectroscopy, Phys. Rev. B 57(1998) 2536-2540; DOI: 10.1103/PhysRevB.57.2536.

38. T. Ujvári, A. Kolitsch, A. Tóth, M. Mohai, I. Bertóti, XPS characterisation of the composition and bonding states of elements in $\mathrm{CN}_{\mathrm{x}}$ layers prepared by ion beam assisted deposition, Diamond Relat. Mater. 11 (2002) 1149-1152.

39. D. Marton, K.J. Boyd, J.W. Rabalais, Synthesis of carbon nitride, Int. J. Modern Physics B 9 (1995), 3527-3558; DOI: 10.1142/S0217979295001385.

40. R. Larciprete, S. Gardonio, L. Petaccia, S. Lizzit, Atomic oxygen functionalization of double walled C nanotubes, Carbon 47 (2009) 2579-2589.

41. J-H. Zhou, Z-J. Sui, J. Zhu, P. Li, D. Chen, Y.-C. Dai et al., Characterization of surface oxygen complexes on carbon nanofibers by TPD, XPS and FT-IR, Carbon 45 (2007) $785-796$.

42. U. Zielke, K.J. Hüttinger, W.P. Hoffman, Surface-oxidized carbon fibers: IV. Interaction with high-temperature thermoplastics, Carbon 34, (1996) 1015-1026.

43. Z.R. Yue, W. Jiang, L. Wang, S.D. Gardner, C.U. Pittman Jr., Surface characterization of electrochemically oxidized carbon fibers, Carbon 37 (1999) 1785-1796. 
44. P.V. Lakshminarayanan, H. Toghiani, C.U. Pittman Jr., Nitric acid oxidation of vapor grown carbon nanofibers, Carbon 42 (2004) 2433-2442.

45. S.E. Rodil, S. Muhl, Bonding in amorphous carbon nitride, Diamond Relat. Mater. 13 (2004) 1521-1531; DOI: 10.1016/j.diamond.2003.11.008.

46. C. Ronning, H. Feldermann, R. Merk, H. Hofsass, H.P. Reinke, J.U. Thiele, Carbon nitride deposited using energetic species: A review on XPS studies, Phys.Rev.B 58 (1998) 2207-2215; DOI: 10.1103/PhysRevB.58.2207.

47. H.K. Jeong, Y.P. Lee, R.J. Lahaye, M.H. Park, K.H. An, I.J. Kim et al., Evidence of Graphitic AB Stacking Order of Graphite Oxides, J. Am. Chem. Soc. 130 (2008) 13621366.

48. D. Yang, A. Velamakanni, G. Bozoklu, S. Park, M. Stoller, R.D. Piner, et al., Chemical analysis of graphene oxide films after heat and chemical treatments by X-ray photoelectron and Micro-Raman spectroscopy, Carbon 47 (2009) 145-152.

49. A.P. Dementjev, A. de Graaf, M.C.M. van de Sanden, K.I. Maslakov, A.V. Naumkin, A.A. Serov, X-ray photoelectron spectroscopy reference data for identification of the $\mathrm{C}_{3} \mathrm{~N}_{4}$ phase in carbon-nitrogen films, Diamond Relat. Mater. 9 (2000) 1904-1907; DOI: 10.1016/S0925-9635(00)00345-9.

50. H. Dai, X. Gao, E. Liu, Y. Yang, W. Hou, L. Kang et al., Synthesis and characterization of graphitic carbon nitride sub-microspheres using microwave method under mild condition, Diamond Relat. Mater. 38 (2013) 109-117; DOI:

10.1016/j.diamond.2013.06.012.

51. R.C. Dante, P. Martín-Ramos, A. Correa-Guimaraes, J. Martín-Gil, Synthesis of graphitic carbon nitride by reaction of melamine and uric acid, Mat. Chem. Phys. 130 (2011) 1094-1102, DOI: 10.1016/j.matchemphys.2011.08.041.

52. Y. Zhao, Z. Liu, W. Chu, L. Song, Z. Zhang, Dongli Yu et al., Large-Scale Synthesis of Nitrogen-Rich Carbon Nitride Microfibers by Using Graphitic Carbon Nitride as Precursor, Adv. Mater. 20 (2008) 1777-1781, DOI: 10.1002/adma.200702230.

53. C. Zhang, R. Hao, H. Liao, Y. Hou, Synthesis of amino-functionalized graphene as metal-free catalyst and exploration of the roles of various nitrogen states in oxygen reduction reaction, Nano Energy 2 (2013) 88-97; DOI: 10.1016/j.nanoen.2012.07.021. 
54. Y-C. Lin, Ch-Y. Lin, P-W. Chiu, Controllable graphene N-doping with ammonia plasma, Appl. Phys. Lett. 96 (2010) 133110-133110-3; DOI: 10.1063/1.3368697.

55. A. Achour, S. Vizireanu, G. Dinescu, L. Le Brizoual, M.-A. Djouadi, M. Boujtita, Electrochemical anodic oxidation of nitrogen doped carbon nanowall films: X-ray photoelectron and Micro-Raman spectroscopy study, Appl. Surf. Sci. 273 (2013) 49-57.

56. G. Beamson, D. Briggs, High Resolution XPS of Organic Polymers — The Scienta ESCA300 Database, Wiley, Chichester (1992).

57. W.J. Gammon, O. Kraft, A.C. Reilly, B.C. Holloway, Experimental comparison of N(1s) $\mathrm{X}$-ray photoelectron spectroscopy binding energies of hard and elastic amorphous carbon nitride films with reference organic compounds, Carbon 41 (2003) 1917-1923. 


\section{Supplementary Information}

Table S1 Assignation of the C1s, N1s and O1s lines in the literature for the variously treated nanocarbon meterials [5,14,40,41,47,48,53-57].

\begin{tabular}{|c|c|c|c|c|}
\hline \multicolumn{2}{|c|}{ Energy $(e V)$} & Sample & Assignation & Ref \\
\hline \multicolumn{5}{|c|}{ C 1s lines } \\
\hline \multicolumn{2}{|l|}{284.3} & pristine graphene & $\mathrm{sp}^{2} \mathrm{C}-\mathrm{C}$ & 47 \\
\hline \multicolumn{2}{|l|}{284.3} & $\mathrm{NH}_{3}$ plasma graphene & pure $\mathrm{sp}^{2} \mathrm{C}-\mathrm{C}$ & 54 \\
\hline \multicolumn{2}{|l|}{284.43} & pristine DWCNT & $\mathrm{sp}^{2} \mathrm{C}-\mathrm{C}$ & 40 \\
\hline \multicolumn{2}{|l|}{284.5} & pristine graphene & $\mathrm{sp}^{2} \mathrm{C}-\mathrm{C}$ & 14 \\
\hline \multicolumn{2}{|l|}{284.5} & $\mathrm{~N}$-doped nanowall film & $\mathrm{C}=\mathrm{C}$ & 55 \\
\hline \multicolumn{2}{|l|}{284.6} & carbon nanofiber & graphitic C & 41 \\
\hline \multicolumn{2}{|l|}{284.7} & $\mathrm{NH}_{3}$ plasma graphene & disordered $\mathrm{sp}^{2} \mathrm{C}-\mathrm{C}$ & 47 \\
\hline \multicolumn{2}{|l|}{284.7} & $\mathrm{NH}_{3}$ plasma graphene & disordered $\mathrm{C}-\mathrm{C}$ & 54 \\
\hline \multicolumn{2}{|l|}{284.75} & oxidised DWCNT & distorted $\mathrm{sp}^{2} \mathrm{C}-\mathrm{C}$ & 40 \\
\hline \multicolumn{2}{|l|}{284.8} & $\mathrm{~N}$-doped graphene & $\mathrm{C}-\mathrm{C}$ & 5 \\
\hline \multicolumn{2}{|l|}{284.8} & $\mathrm{NH}_{2}$ functionalized graphene & $\mathrm{C}-\mathrm{C}$ & 50 \\
\hline \multirow{2}{*}{\multicolumn{2}{|c|}{$\frac{284.8 \pm 0.3}{285.0}$}} & graphene oxide & $\mathrm{C}-\mathrm{C}, \mathrm{C}-\mathrm{H}$ & 48 \\
\hline & & graphite oxide & $\mathrm{sp}^{2} \mathrm{C}$ & 47 \\
\hline \multicolumn{2}{|l|}{285.2} & pristine graphene & $\mathrm{sp}^{3} \mathrm{C}-\mathrm{C}, \mathrm{C}-\mathrm{H}$ & 14 \\
\hline \multicolumn{2}{|l|}{285.30} & oxidised DWCNT & $\mathrm{sp}^{3} \mathrm{C}$ & 40 \\
\hline \multicolumn{2}{|l|}{285.4} & oxidised graphene & $\mathrm{C}-\mathrm{OH}$ & 14 \\
\hline \multicolumn{2}{|l|}{285.5} & N-doped nanowall film & $\mathrm{C}-\mathrm{C}, \mathrm{C}-\mathrm{H}$ & 55 \\
\hline \multicolumn{2}{|l|}{285.8} & $\mathrm{NH}_{3}$ plasma graphene & $\mathrm{sp}^{2} \mathrm{C}-\mathrm{N}$ & 47 \\
\hline \multicolumn{2}{|l|}{285.8} & $\mathrm{NH}_{2}$ functionalized graphene & $\mathrm{C}-\mathrm{N}$ & 50 \\
\hline \multicolumn{2}{|l|}{285.8} & $\mathrm{NH}_{3}$ plasma graphene & $\mathrm{sp}^{2} \mathrm{C}-\mathrm{N}$ & 54 \\
\hline \multicolumn{2}{|l|}{285.9} & $\mathrm{~N}$-doped graphene & $\mathrm{C}-\mathrm{OH}$ & 5 \\
\hline \multicolumn{2}{|l|}{286.3} & graphene oxide & $\mathrm{C}-\mathrm{OH}$, epoxide & 48 \\
\hline \multicolumn{2}{|l|}{286.4} & oxidised DWCNT & $\mathrm{C}-\mathrm{O}-\mathrm{C}$ (epoxy, ether) & 40 \\
\hline \multicolumn{2}{|l|}{286.6} & oxidised graphene & $\mathrm{C}-\mathrm{O}-\mathrm{C}$ epoxy & 14 \\
\hline \multicolumn{2}{|c|}{$286.6 \pm 0.3$} & graphite oxide & $\mathrm{C}-\mathrm{OH}$ & 47 \\
\hline 286.6 & +0.3 & carbon nanofiber & phenolic, $\mathrm{C}-\mathrm{OH}, \mathrm{C}-\mathrm{O}-\mathrm{C}, \mathrm{C}=\mathrm{N}$ & 41 \\
\hline 286.8 & & $\mathrm{NH}_{2}$ functionalized graphene & $\mathrm{C}-\mathrm{O}$ & 50 \\
\hline 286.9 & & N-doped nanowall film & $\mathrm{C}-\mathrm{OH}$, epoxide, $\mathrm{C}-\mathrm{N}$ & 55 \\
\hline 287.1 & & N-doped graphene & $\mathrm{C}=\mathrm{O}$ & 5 \\
\hline 287.1 & & $\mathrm{NH}_{3}$ plasma graphene & $\mathrm{sp}^{3} \mathrm{C}-\mathrm{N}$ & 47 \\
\hline 287.1 & & $\mathrm{NH}_{3}$ plasma graphene & $\mathrm{sp}^{3} \mathrm{C}-\mathrm{N}$ & 54 \\
\hline 287.3 & & graphene oxide & $\mathrm{C}=\mathrm{O}$ & 48 \\
\hline 287.3 & +0.3 & carbon nanofiber & $\mathrm{O}=\mathrm{C}$, quinine & 41 \\
\hline 287.5 & \pm 0.5 & N-doped graphene & $\mathrm{C}-\mathrm{N}$ & 5 \\
\hline 287.5 & \pm 0.3 & graphite oxide & $\mathrm{O}-\mathrm{C}-\mathrm{O}$ & 47 \\
\hline 287.6 & & oxidised graphene & $\mathrm{C}=\mathrm{O}$ carbonyl & 14 \\
\hline 287.8 & & oxidised DWCNT & $\mathrm{C}=\mathrm{O}$ (carbonyl, ketone, quinone) & 40 \\
\hline 287.8 & & $\mathrm{NH}_{2}$ functionalized graphene & $\mathrm{C}=\mathrm{O}$ & 50 \\
\hline 288.6 & & N-doped nanowall film & $\mathrm{C}=\mathrm{O}$ carbonyl & 55 \\
\hline 288.8 & & graphene oxide & $\mathrm{O}=\mathrm{C}-\mathrm{OH}$ & 48 \\
\hline
\end{tabular}




\begin{tabular}{|c|c|c|c|c|}
\hline 288.8 & +0.3 & carbon nanofiber & carboxyl, ester & 41 \\
\hline 289.0 & & N-doped graphene & $\mathrm{C}-\mathrm{C}=\mathrm{O}$ & 5 \\
\hline 289.0 & & oxidised DWCNT & $\mathrm{O}=\mathrm{C}-\mathrm{O}$ (arboxylate, ester) & 40 \\
\hline 289.0 & & $\mathrm{NH}_{2}$ functionalized graphene & $\mathrm{COOH}$ & 50 \\
\hline 289.3 & \pm 0.3 & graphite oxide & $\mathrm{HO}-\mathrm{C}=\mathrm{O}$ & 47 \\
\hline 290.1 & & N-doped nanowall film & $\mathrm{O}=\mathrm{C}-\mathrm{OH}$ carbonate & 55 \\
\hline 290.5 & +0.7 & carbon nanofiber & $\mathrm{CO}_{3}$, adsorbed $\mathrm{CO}$ and $\mathrm{CO}_{2}$ & 41 \\
\hline 291.0 & & oxidised DWCNT & $\pi-\pi^{*}$ shake up & 40 \\
\hline 291.6 & & N-doped nanowall film & $\pi-\pi^{*}$ shake up & 55 \\
\hline \multicolumn{5}{|l|}{ N1s lines } \\
\hline 397.4 & \pm 0.9 & oxidised nanowall film & $\mathrm{N}-\mathrm{N}$, pyridinic & 55 \\
\hline 398.3 & & $\mathrm{NH}_{3}$ plasma graphene & pyridinic $\mathrm{N}$ & 47 \\
\hline 398.3 & & $\mathrm{NH}_{2}$ functionalized graphene & pyridinic $\mathrm{N}$ & 50 \\
\hline 398.3 & & $\mathrm{NH}_{3}$ plasma graphene & pyridine-like $\mathrm{N}$ & 54 \\
\hline 398.9 & & N-doped graphene & pyridinic $\mathrm{N}$ & 5 \\
\hline 399.0 & & $\mathrm{NH}_{3}$ plasma graphene & NH in hexagonal ring & 47 \\
\hline 399.0 & & $\mathrm{NH}_{3}$ plasma graphene & $-\mathrm{NH}_{2}$ & 54 \\
\hline 399.2 & & $\mathrm{NH}_{2}$ functionalized graphene & $-\mathrm{NH}_{2}$ & 50 \\
\hline 400.1 & & N-doped graphene & pyrrolic N & 5 \\
\hline 400.1 & & $\mathrm{NH}_{2}$ functionalized graphene & pyrrolic N & 50 \\
\hline 400.2 & & $\mathrm{NH}_{3}$ plasma graphene & pyrrolic N (pentagonal ring) & 47 \\
\hline 400.2 & & $\mathrm{NH}_{3}$ plasma graphene & pyrrole-like $\mathrm{N}$ & 54 \\
\hline 400.5 & & oxidised nanowall film & pyrrolic, pyridone & 55 \\
\hline 401.4 & & $\mathrm{NH}_{3}$ plasma graphene & quaternary $\mathrm{N}, \mathrm{sp}^{2} \mathrm{~N}$ in rings & 47 \\
\hline 401.4 & & $\mathrm{NH}_{2}$ functionalized graphene & $\mathrm{N}$ in rings & 50 \\
\hline 401.4 & & $\mathrm{NH}_{3}$ plasma graphene & quaternaryl $\mathrm{N}, \mathrm{sp}^{2} \mathrm{~N}$ in rings & 54 \\
\hline 401.5 & & N-doped graphene & quaternary $\mathrm{N}$ & 5 \\
\hline 403.7 & & $\mathrm{NH}_{2}$ functionalized graphene & oxidized nitrogen & 50 \\
\hline 404.1 & & oxidised nanowall film & $\mathrm{N}-\mathrm{O}$ & 55 \\
\hline \multicolumn{5}{|l|}{ O1s lines } \\
\hline 530.0 & & oxidised nanowall film & $\mathrm{O}=\mathrm{C}-\mathrm{OH}$, adsorbed $\mathrm{O}$ & 55 \\
\hline 530.6 & & graphene oxide & $\mathrm{C}=\mathrm{O}, \mathrm{O}=\mathrm{C}-\mathrm{OH}$ & 48 \\
\hline 531.0 & +0.9 & carbon nanofiber & quinine & 41 \\
\hline 531.18 & & oxidised DWCNT & $\mathrm{C}=\mathrm{O}$ & 40 \\
\hline 531.3 & & oxidised nanowall film & $\mathrm{C}=\mathrm{O},-\mathrm{OH}$ free radical & 55 \\
\hline 531.8 & & N-doped graphene & $\mathrm{COOH}$ & 5 \\
\hline 532.15 & & oxidised DWCNT & $\mathrm{C}-\mathrm{O}-\mathrm{C}$ epoxy & 40 \\
\hline 532.3 & +0.5 & carbon nanofiber & $\mathrm{OH}, \mathrm{C}=\mathrm{O}$ in ester, anhydride & 41 \\
\hline 532.5 & & N-doped graphene & $\mathrm{C}=\mathrm{O}$ & 5 \\
\hline 533.0 & & graphene oxide & $\mathrm{C}-\mathrm{OH}$ & 48 \\
\hline 533.1 & +0.7 & carbon nanofiber & $\mathrm{C}-\mathrm{O}-\mathrm{C}$ in ester, anhydride & 41 \\
\hline 533.3 & & oxidised nanowall film & $\mathrm{C}-\mathrm{OH}, \mathrm{C}-\mathrm{O}-\mathrm{C}$ & 55 \\
\hline 533.38 & & oxidised DWCNT & $\mathrm{C}-\mathrm{O}-\mathrm{C}, \mathrm{O}=\mathrm{C}-\mathrm{O}^{*}$ & 40 \\
\hline 533.9 & & N-doped graphene & $\mathrm{C}-\mathrm{OH}$ & 5 \\
\hline
\end{tabular}




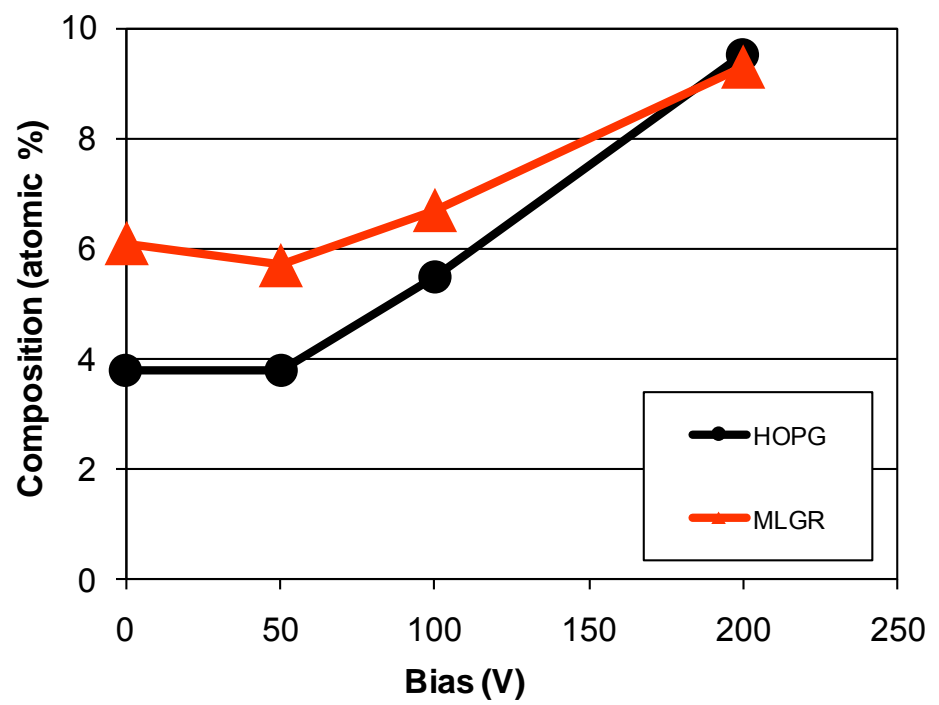

Fig. S1 The change of surface nitrogen concentration of the MLGR and HOPG samples at increasing bias between $0-200 \mathrm{~V}$ for 10 min reaction time.
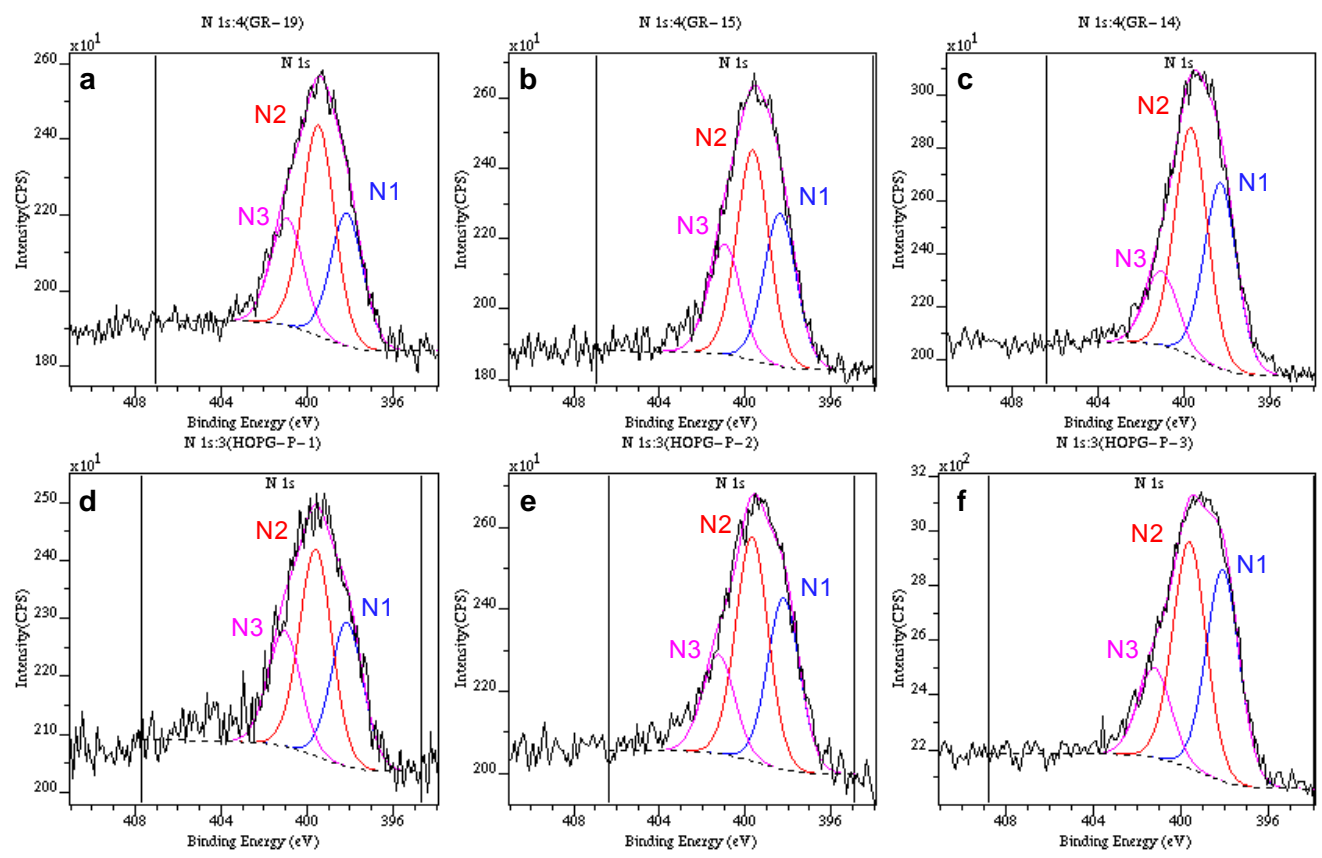

Fig. S2 Decomposition of the high-resolution XP spectra of the N1s region for the MLGR (ac) and HOPG (d-f) samples treated at 50, 100 and $200 \mathrm{~V}$ bias, respectively. 
Imre Bertóti, Miklós Mohai, Krisztina László

Surface modification of graphene and graphite by nitrogen plasma:

Determination of chemical state alterations and assignments by quantitative X-ray photoelectron spectroscopy

Carbon, 84, 185-196, 2015
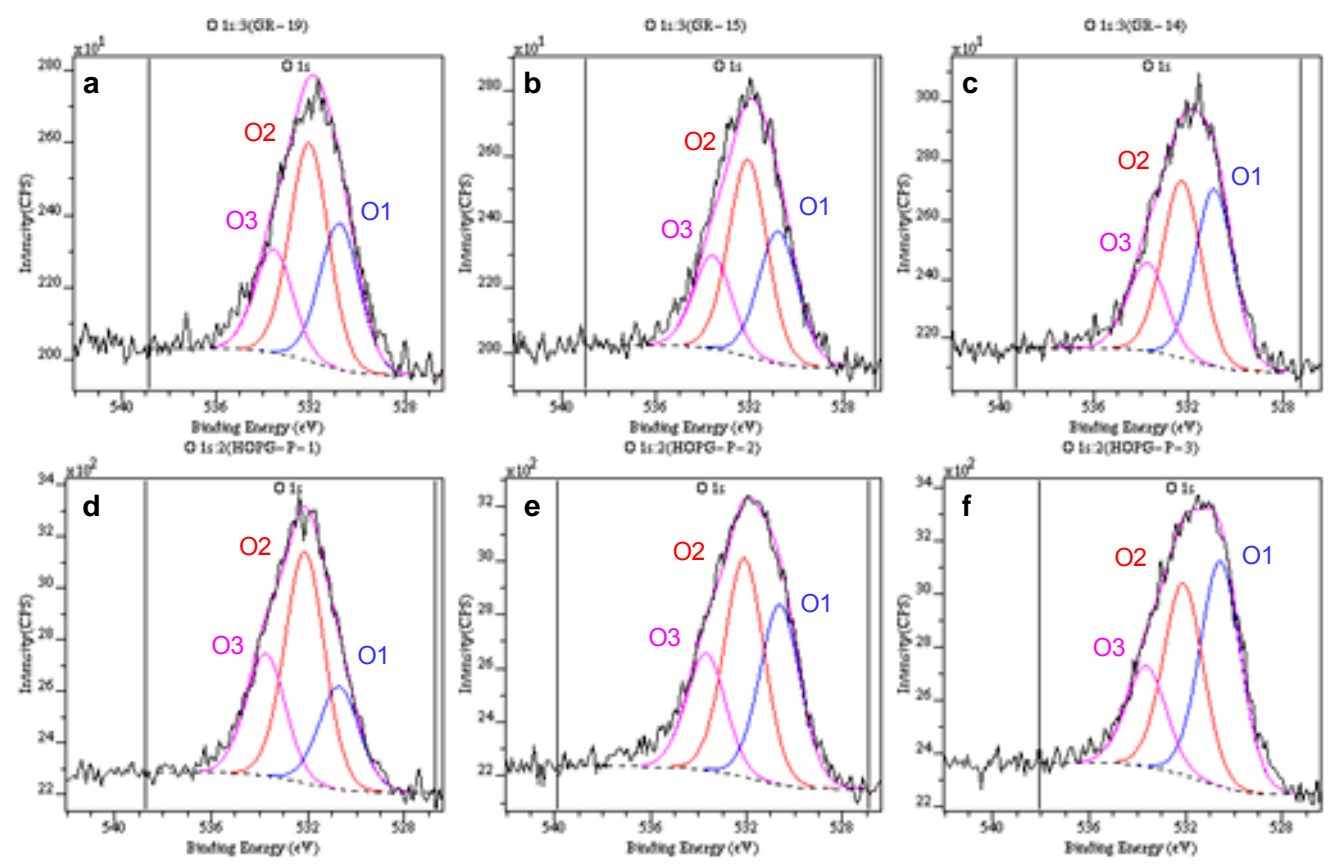

Fig. S3 Decomposition of the high-resolution XP spectra of the O1s region of the MLGR $(a-c)$ and HOPG (d-f) samples treated at 50, 100 and $200 \mathrm{~V}$ bias, respectively. 